\title{
Manajemen Usaha Pengolahan Ikan Pindang Di Poklahsar Pindang Panjul Segara Kabupaten Tabanan Provinsi Bali
}

\author{
[Processing Business Management of Pindang Fish in Poklahsar Pindang \\ Panjul Segara Tabanan District Bali Province]
}

Diah Ayu Meriana Sari, Yenni Nuraini

\author{
Program Studi Penyuluhan Perikanan, Politeknik Ahli Usaha Perikanan \\ Jalan Cikaret No. 2 Kota Bogor 16132
}

\begin{abstract}
Abstrak
Ikan adalah salah satu bahan pangan yang baik untuk dikonsumsi, namun komoditas ini bersifat mudah rusak, sehingga diperlukan tindakan penanganan yang cepat, tepat, dan benar setelah panen. Pengolahan ikan pindang dilakukan dengan perebusan dan penggaraman di dalam suatu wadah selama jangka waktu tertentu. Penelitian dilakukan untuk mengetahui sistem bisnis usaha dan teknologi pengolahan ikan pindang di Poklahsar Pindang Panjul Segara. Poklahsar Pindang Panjul Segara adalah salah satu kelompok pengolah dan pemasar yang berlokasi di Desa Sudimara Kecamatan Tabanan Kabupaten Tabanan Provinsi Bali. Penelitian dilakukan selama 30 hari mulai dari tanggal 12 September 2020 sampai dengan 11 Oktober 2020 dengan sasaran tiga responden dari anggota kelompok. Analisis data dilakukan dengan metode analisis data kuantitatif dan kualitatif yang dianalisis secara deskriptif. Analisis data meliputi aspek sistem bisnis pengolahan ikan pindang dan analisis usaha yang meliputi komponen pendapatan, keuntungan, dan analisis kelayakan usaha $\mathrm{R} / \mathrm{C}$ ratio, $\mathrm{PP}, \mathrm{ROI}$, dan $\mathrm{BEP}$. Usaha pengolahan ikan pindang dilakukan mulai dari penyediaan pasokan input, proses produksi, pasca produksi hingga pemasaran. Ketersediaan bahan baku, modal dan tenaga kerja serta penyediaan sarana dan prasarana telah terpenuhi sehingga kegiatan terlaksana dengan baik. Proses produksi dilakukan melalui proses yang cukup baik sehingga menghasilkan produk ikan pindang yang layak dikonsumsi. Analisis usaha menunjukkan usaha pengolahan ikan pindang layak untuk dilanjutkan.
\end{abstract}

Kata Kunci : ikan pindang; manajemen usaha; pengolahan

\section{Abstract}

Fish is one of the best consumable comodity, but it needs very carefull processing approach due to its perishable food character. Pindang fish processing is done by boiling and salting it in a container for a certain period of time. This research aims to determine the processing technology and business system of pindang fish in Poklahsar Pindang Panjul Segara. Poklahsar Pindang Panjul Segara is a group of fish processing and marketing which located in Sudimara Village, Tabanan, Bali. The research was conducted for 30 days which took place from 12 September 2020 to 11 October 2020 with the target of three respondents from one group member. The data analysis methods in this study were quantitative and qualitative which were analyzed descriptively. Data. Data analysis were done in the aspects of pindang fish processing system and its business which includes components of income, profit, and business feasibility analysis of $\mathrm{R}$ / $\mathrm{C}$ ratio, PP, ROI, and BEP. The pindang fish processing business covers input supply, production process, and post-production to marketing. The availability of raw materials, capital and labor as well as the provision of facilities and infrastructure have been fulfilled so that activities are carried out properly. The production process run through a fairly good process to produce consumable pindang fish products. Based on business analysis point of view, showed pindang fish processing in this group is feasible to be continued

Keywords: ikan pindang; business management; processing 
Penulis Korespondensi

Diah Ayu Meriana Sari | diahayumeri99@gmail.com

\section{PENDAHULUAN}

Ikan adalah salah satu bahan pangan yang baik untuk dikonsumsi, namun, komoditas ini sifatnya mudah rusak (perishable food). Ikan dikategorikan sebagai produk yang cepat busuk (highly perishable), sehingga diperlukan tindakan penanganan yang cepat, tepat, dan benar setelah panen. Apabila tidak ditangani dengan baik, maka kemunduran kualitas produk akan berjalan relatif cepat.

Pengolahan dan pengawetan ikan bertujuan mempertahankan mutu dan kesegaran ikan selama mungkin dengan cara menghambat atau menghentikan penyebab kemunduran mutu atau penyebab kerusakan ikan agar ikan tetap baik sampai ke tangan konsumen (Pudjanarso 2015), sehingga ikan perlu diolah untuk meningkatkan dan memperbaiki nilai ekonomisnya. Pada kondisi demikian, peran penanganan dan pengolahan menjadi sangat penting untuk peningkatan volume produksi serta pengembangan usaha perikanan.

Salah satu olahan ikan tradisional yang masih banyak diminati saat ini adalah ikan pindang. Ikan pindang adalah istilah untuk olahan ikan menggunakan teknik pemindangan. Proses pemindangan ikan dilakukan dengan perebusan dan penggaraman di dalam suatu wadah selama jangka waktu tertentu (Pudjanarso 2015).

Ikan pindang menjadi produk unggulan pengolahan hasil perikanan di Provinsi Bali. Pengolahan ikan pindang di Provinsi Bali tersebar di delapan Kabupaten/Kota, salah satunya adalah Kabupaten Tabanan. Produksi ikan pindang di Kabupaten Tabanan pada tahun 2015 mencapai 2.022,7 ton dengan nilai produksi sebesar Rp 56.484.897,00. Salah satu kelompok pengolah dan pemasar (Poklahsar) ikan pindang di Kabupaten Tabanan adalah Poklahsar Pindang Panjul Segara yang berlokasi di Desa Sudimara Kecamatan Tabanan Kabupaten Tabanan Provinsi Bali. Penelitian ini bertujuan untuk mengetahui sistem bisnis usaha dan teknologi pengolahan pemindangan ikan di Poklahsar Pindang Panjul Segara.

\section{BAHAN DAN METODE}

Penelitian dilaksanakan di Poklahsar Pindang Panjul Segara di Desa Sudimara Kecamatan Tabanan Kabupaten Tabanan Provinsi Bali. Penelitian dilakukan selama 30 hari mulai dari tanggal 12 September 2020 sampai dengan 11 Oktober 2020 dengan sasaran anggota kelompok Poklahsar Pindang Panjul 
Segara yang diambil sampel sebanyak tiga responden.

Data yang diambil terdiri dari dua jenis data yaitu data primer dan data sekunder. Data primer diperoleh dari hasil observasi dan wawancara dengan narasumber yang berada di lokasi penelitian, sedangkan data sekunder diperoleh dari hasil studi pustaka, analisis catatan/ laporan dan dokumentasi.

Data dikumpulkan dengan metode wawancara, pengamatan, penelusuran data sekunder dan dokumentasi. Analisis data dilakukan dengan dua metode yaitu analisis data kuantitatif dan kualitatif. Data kuantitatif adalah data numerik yang dapat ukur, sedangkan data kualitatif adalah data yang tidak berbentuk angka melainkan hanya berupa keterangan dan informasi. Kedua data ini akan dianalisis secara deskriptif.

Bahan yang digunakan dalam kegiatan penelitian ini adalah analisis usaha dengan perhitungan nilai biaya investasi, biaya produksi, Revenue Cost Ratio (R/C Ratio), Payback Period (PP) dan Break Event Point (BEP), Return of Invesment (ROI).

\section{Revenue Cost Ratio (R/C Ratio)}

$\mathrm{R} / \mathrm{C}$ ratio adalah salah satu analisa usaha untuk mengukur kelayakan suatu usaha dimana menekankan pada penerimaan dan beberapa jenis pengeluaran (Wijayanto dan Kurohman 2018) yang menggunakan formula perhitungan sebagai berikut yaitu :

$$
\mathrm{R} / \mathrm{C}=\frac{\text { Penerimaan }}{\text { Pengeluaran }}
$$

\section{Payback Period (PP)}

Payback period merupakan periode yang diperlukan untuk menutup kembali pengeluaran investasi (Judhaswati dan Damayanti 2018). Payback period (PP) adalah analisa untuk mengetahui rentang waktu yang diperlukan bagi aliran tunai yang dihasilkan oleh suatu kegiatan investasi untuk menutup semua biaya/modal awalnya (Setiawan et al. 2018), dengan menggunakan kriteria:

$$
\mathrm{PP}=\frac{\text { Investasi }}{\text { Kas bersih per tahun }} \times 1 \text { tahun }
$$

Metode PP merupakan teknik penilaian terhadap jangka waktu (periode) pengembalian investasi suatu proyek atau usaha. Kriteria :

- Nilai PP kurang dari tiga tahun kategori pengembalian cepat

- Nilai PP tiga sampai lima tahun kategori pengembalian sedang

- Nilai PP lebih dari lima tahun kategori lambat.

\section{Break Event Point (BEP)}

Break Event Point (BEP) adalah suatu keadaan dimana modal telah kembali semua atau pengeluaran sama dengan pendapatan. Analisis Break Even Point bertujuan untuk menentukan suatu 
titik baik dalam unit maupun rupiah yang menunjukkan biaya sama dengan pendapatan (Setiawan et al. 2018). Dengan mengetahui titik tersebut, berarti belum diperoleh keuntungan atau dengan kata lain tidak untung dan tidak rugi. Penghitungan BEP tersebut dapat dinyatakan dengan rumus:

$$
\begin{gathered}
\operatorname{BEP}(\mathrm{Rp})=\frac{\text { Biaya tetap }}{1-\frac{\text { Biaya variable }}{\text { Penjualan }}} \\
\operatorname{BEP}(\text { Unit })=\frac{\text { Biaya tetap }}{\text { Harga satuan-Biaya Variabel }}
\end{gathered}
$$

\section{Return of Investment (ROI)}

ROI merupakan parameter untuk mengetahui tingkat pengembalian investasi dari penerimaan (benefit) yang diterima pemilik (Fauzi et al. 2011). Kegiatan perikanan layak dikembangkan bila mempunyai nilai ROl>1 (satu). Perhitungan nilai $\mathrm{ROI}$ menggunakan rumus: analisis Return of invesment dapat dihitung dengan rumus dibawah ini:

$$
\text { ROI }=\frac{\text { Laba Usaha }}{\text { Biaya Produksi }}
$$

\section{HASIL DAN PEMBAHASAN \\ Hasil \\ Kondisi Umum Lokasi Usaha}

Desa Sudimara merupakan salah satu desa yang terletak di Kecamatan Tabanan Kabupaten Tabanan Provinsi Bali. Desa Sudimara merupakan daerah dataran rendah dengan ketinggian $10 \mathrm{~m}$ di atas permukaan laut. Desa Sudimara memiliki batas wilayah desa yaitu sebelah utara adalah Desa Gubug, sebelah selatan adalah Samudera Hindia, sebelah timur adalah Desa Bengkel dan Desa Bongan dan sebelah barat adalah Desa Penarukan dan Desa Kelating. Desa Sudimara memiliki luas $583 \mathrm{Ha}$ dengan berbagai peruntukan seperti sawah, ladang, pemukiman, pekarangan dan fasilitas umum. Tanah sawah di Sesa Sudimara cukup besar yaitu seluas $368 \mathrm{Ha}$, sehingga sebagian besar penduduk bekerja pada sektor pertanian. Selain itu penduduk juga memiliki mata pencaharian di bidang perikanan, dagang, buruh dan jasa.

\section{Profil Poklahsar Pindang Panjul Segara Kelompok Pengolah dan Pemasar} (Poklahsar) Pindang Panjul Segara merupakan salah satu kelompok perikanan yang berlokasi di Banjar Yeh Gangga, Desa Sudimara, Kecamatan Tabanan, Kabupaten Tabanan, Provinsi Bali. Poklahsar Pindang Panjul Segara berdiri pada tanggal 11 April 2011dengan jumlah anggota di tahun tersebut tercatat sebanyak 44 orang.

\section{Poklahsar Pindang Panjul Segara} bergerak di bidang usaha pengolahan ikan, yaitu ikan pindang. Kegiatan usaha dilakukan secara mandiri di tempat masing-masing setiap anggota kelompok. Artinya, setiap anggota melakukan 
proses produksi hingga pemasaran secara mandiri. Ketua kelompok memiliki peran yang penting sebagai penyedia bahan baku ikan.

\section{Identifikasi Sistem Usaha Pengolahan Pemindangan Ikan di Poklahsar Pindang Panjul Segara}

Identifikasi sistem usaha pengolahan pemindangan ikan di Poklahsar Pindang Panjul Segara meliputi sub sistem pasokan input, sub sistem proses produksi, sub sistem pasca produksi, sub sistem pemasaran dan sub layanan pendukung.

\section{Sub Sistem Pasokan Input}

Angota kelompok pada awal merintis usaha menggunakan modal sendiri. Salah satu pemindang, yaitu Ibu Dewa Komang Muliastiti yang sudah hampir 20 tahun menjalankan usahanya, pertama kali menggunakan modal senilai Rp 50.000. Pemindang kemudian meminjam modal berupa uang atau barang melalui sanak keluarga atau tetangga terdekat dan kemudian baru pada lembaga permodalan.

Bahan baku ikan pindang adalah ikan laut mentah baik segar maupun beku. Terdapat enam jenis ikan yang digunakan sebagai bahan baku ikan pindang oleh pemindang, diantaranya adalah ikan kocing (ikan lemuru), ikan selungsung, ikan tongkol, ikan kenyar, ikan baby tuna dan ikan suat (ikan cakalang). Adapun ukuran ikan tergantung dari jenisnya, untuk ikan lemuru berkisar antara 14-20 ekor per kg, ikan selungsung dan tongkol 3-4 ekor per kg, ikan kenyar dan baby tuna 2-3 ekor per kg dan ikan cakalang 1 ekor per kg. Produksi dilakukan sebanyak 25 kali dalam sebulan. Dalam 1 siklus produksi, pemindang dapat menghabiskan bahan baku lebih dari dua kwintal. Selain ikan, garam menjadi hal yang penting dalam proses produksi ikan pindang. Jenis garam yang digunakan adalah garam krotok atau garam krosok, dengan kisaran harga Rp1.500 per kg.

Para pemindang, yaitu ibu-ibu rumah tangga melakukan kegiatan usahanya sendiri ataupun dibantu oleh suaminya. Selain itu, terdapat juga pemindang yang mengajak tenaga kerja untuk membantu menjalankan usahanya.

\section{Sub Sistem Proses Produksi}

Teknik pengolahan ikan pindang dilakukan dengan teknik pemindangan garam. Wadah yang digunakan berupa baskom kedap air. Proses pemindangan mulai dari persiapan bahan baku, persiapan peralatan dan bahan, pembersihan dan pencucian, penggaraman dan penyusunan ikan, perebusan ikan dan penyimpanan. Ikan lemuru, ikan selungsung, ikan kenyar, ikan baby tuna dan ikan tongkol disusun utuh tanpa disiangi dalam wadah baskom, sedangkan untuk ikan cakalang dipotong-potong menjadi 
beberapa bagian dan direbus dengan lebih banyak air. Pindang yang dipotongpotong ini biasa disebut pindang cekalan. Satu wadah baskom berisi kurang lebih $10 \mathrm{~kg}$ ikan.

\begin{abstract}
Sub Sistem Pasca Produksi
Wadah baskom digunakan untuk merebus, sekaligus digunakan untuk menyimpan ikan yang akan dipasarkan. Hal ini dikarenakan ikan pindang dijual per ekor menurut jenisnya. Ketika konsumen hendak membeli, barulah ikan pindang diambil satu persatu dari baskom lalu dibungkus kantong plastik.
\end{abstract}

Tabel 1. Profil Pemindang

\begin{tabular}{llccc}
\hline No & Nama Pemindang & Kode & $\begin{array}{c}\text { Hari Mengolah } \\
\text { dalam sebulan }\end{array}$ & $\begin{array}{c}\text { Jumlah Bahan } \\
\text { Baku (kg) }\end{array}$ \\
\hline 1 & Ni Wayan Baker & A & 25 & 210 \\
2 & Dewa Komang Muliastiti & B & 25 & 190 \\
3 & Ni Wayan Sokowati & C & 25 & 120 \\
\hline
\end{tabular}

Tabel 2. Perbandingan Analisis Usaha

\begin{tabular}{llcrrr}
\hline No & \multicolumn{1}{c}{ Keterangan } & Satuan & \multicolumn{1}{c}{ A } & \multicolumn{1}{c}{ B } & \multicolumn{1}{c}{ C } \\
\hline 1 & Biaya investasi & $\mathrm{Rp}$ & 168.835 .000 & 191.004 .000 & 164.754 .000 \\
2 & Penyusutan & $\mathrm{Rp}$ & 925.750 & 1.201 .583 & 909.569 \\
3 & Biaya tetap & $\mathrm{Rp}$ & 2.235 .750 & 2.361 .583 & 2.219 .569 \\
4 & Biaya variabel per hari & $\mathrm{Rp}$ & 4.504 .500 & 4.154 .000 & 2.704 .500 \\
5 & Biaya variabel per bulan & $\mathrm{Rp}$ & 112.612 .500 & 103.850 .000 & 67.612 .500 \\
6 & Biaya total per bulan & $\mathrm{Rp}$ & 114.848 .250 & 106.211 .583 & 69.832 .069 \\
7 & Pendapatan per hari & $\mathrm{Rp}$ & 5.220 .000 & 4.770 .000 & 3.120 .000 \\
8 & Pendapatan per bulan & $\mathrm{Rp}$ & 130.500 .000 & 119.250 .000 & 78.000 .000 \\
9 & Keuntungan per hari & $\mathrm{Rp}$ & 626.070 & 521.537 & 326.717 \\
10 & Keuntungan per bulan & $\mathrm{Rp}$ & 15.651 .750 & 13.038 .417 & 8.167 .931 \\
11 & Keuntungan per tahun & $\mathrm{Rp}$ & 187.821 .000 & 156.461 .000 & 98.015 .166 \\
12 & R/C & - & 1,1 & 1,1 & 1,1 \\
13 & Payback period & $\mathrm{Tahun}$ & 0,9 & 1,2 & 1,7 \\
14 & ROI & $\%$ & 13,6 & 12,3 & 11,7 \\
15 & BEP rupiah & $\mathrm{Rp}$ & 15.969 .642 & 18.166 .023 & 17.073 .607 \\
16 & BEP unit & $\mathrm{ekor}$ & & Terlampir & \\
17 & HPP & $\mathrm{RP}$ & Terlampir & & \\
\hline
\end{tabular}


Tabel 3. Perbandingan Jumlah Produksi dan BEP Unit Pemindang

\begin{tabular}{llrrrrrr}
\hline & \multicolumn{2}{c}{ A } & \multicolumn{2}{c}{ B } & \multicolumn{2}{c}{ C } \\
No & \multicolumn{1}{c}{ Nama Ikan } & $\begin{array}{c}\text { Jumlah } \\
\text { Produksi } \\
\text { (ekor) }\end{array}$ & $\begin{array}{c}\text { BEP } \\
\text { unit } \\
\text { (ekor) }\end{array}$ & $\begin{array}{c}\text { Jumlah } \\
\text { Produksi } \\
\text { (ekor) }\end{array}$ & $\begin{array}{c}\text { BEP } \\
\text { unit } \\
\text { (ekor) }\end{array}$ & $\begin{array}{c}\text { Jumlah } \\
\text { Produksi } \\
\text { (ekor) }\end{array}$ & $\begin{array}{c}\text { BEP unit } \\
\text { (ekor) }\end{array}$ \\
\hline 1 & Ikan lemuru & 14.000 & 5.592 & 10.500 & 5.978 & 7.000 & 6.041 \\
2 & Ikan selungsung & 2.400 & 6.111 & 2.250 & 6.872 & 1.500 & 10.340 \\
3 & Ikan tongkol & 6.250 & 5.598 & 5.000 & 6.165 & 4.000 & 7.761 \\
4 & Ikan kenyar & 1.050 & 877 & 1.000 & 938 & 1.000 & 581 \\
5 & Ikan baby tuna & 1.500 & 877 & 1.500 & 939 & 500 & 723 \\
6 & Ikan cakalang & 1.000 & 722 & 750 & 779 & 375 & 839 \\
\hline
\end{tabular}

Tabel 4. Perbandingan Harga Jual dengan HPP Pemindang

\begin{tabular}{llcccc}
\hline No & Nama Ikan & $\begin{array}{c}\text { Harga Jual } \\
\text { (Rp) }\end{array}$ & A & HPP (Rp) & \multicolumn{1}{c}{ C } \\
\hline 1 & Ikan lemuru & 1.500 & 1.260 & 1.330 & 1.450 \\
2 & Ikan selungsung & 8.000 & 8.628 & 8.706 & 9.265 \\
3 & Ikan tongkol & 6.000 & 6.048 & 6.089 & 6.269 \\
4 & Ikan kenyar & 15.000 & 14.687 & 14.845 & 13.398 \\
5 & Ikan baby tuna & 15.000 & 13.942 & 14.059 & 16.367 \\
6 & Ikan cakalang & 24.000 & 23.138 & 24.118 & 27.275 \\
\hline
\end{tabular}

\section{Sub Sistem Pemasaran}

Unsur pertama dalam pemasaran yaitu produk dapat dilihat dari segi kualitas dan kuantitas ikan pindang yang diproduksi. Unsur kedua yaitu harga, dimana harga jual ikan pindang bervariasi berdasarkan jenis dan ukuran ikan. Unsur ketiga yaitu promosi, dimana promosi produk ikan pindang dilakukan secara manual dan sederhana. Unsur keempat yaitu tempat, dimana pemindang memilik dua jalur pemasaran yaitu langsung menjual ke konsumen dan menitipkan ke warung-warung.

\section{Sub Layanan Pendukung.}

Sub sistem lembaga/layanan pendukung mencakup tentang sarana dan prasarana, serta lembaga atau individu yang terkait di dalam suatu kegiatan bisnis perikanan. Alat penunjang dalam proses produksi pengolahan ikan pindang sudah mumpuni untuk melakukan kegiatan usaha. Para pemindang didukung dengan adanya lembaga permodalan dan unit usaha seperti pasar, LPD, KUD, dan Koperasi Simpan Pinjam yang ada di 
Desa Sudimara. Poklahsar Pindang Panjul Segara juga didukung oleh Dinas Perikanan Kabupaten Tabanan.

\section{Analisis Usaha}

Anggota Poklahsar Pindang Panjul Segara melakukan usaha pengolahan ikan pindang masing-masing, sehingga penulis mengambil tiga responden. Rincian pemindang dapat dilihat pada Tabel 1. Ketiga responden diambil berdasarkan karakterisitik yang berbeda. Perbandingan analisis usaha ketiga responden dapat dilihat pada Tabel 2.

Nilai BEP unit dan HPP dihitung per jenis ikan pindang. Terdapat perbedaan yang menunjukkan bahwa terdapat jumlah produksi yang jumlahnya tidak melewati titik impas atau nilai BEP unit. Begitu juga dengan HPP, terdapat harga jual produk yang tidak melewati nilai HPP. Perbandingan nilai BEP dan HPP dapat dilihat pada Tabel 3 dan 4.

\section{Pembahasan}

Identifikasi Sistem Usaha Pengolahan Pemindangan Ikan di Poklahsar Pindang Panjul Segara

Sub sistem pasokan input yang terdiri dari modal, bahan baku dan tenaga kerja. Kualitas dan kuantitas pasokan untuk sistem produksi sudah terpenuhi dengan baik oleh para pemindang, di mana penggunaan input dengan jumlah yang tepat perlu diperhatikan oleh produsen karena mempengaruhi produksi dan biaya produksi (Karmini 2018).

Pemindangan garam adalah ikan dan garam disusun berselang-seling pada wadah yang kedap air yang telah berisi air dalam jumlah sedikit, kemudian dipanaskan di atas nyala api selama jangka waktu tertentu (Assadad dan Utomo 2011). Garam yang digunakan adalah garam krosok yang memiliki butiran kasar berbentuk kristal. Garam ditaburkan secara merata pada setiap lapisan ikan sekitar $4-5 \%$ dari berat ikan, sedangkan menurut (Tim BSE 2017) garam yang digunakan adalah sekitar 5 $25 \%$. Waktu yang dibutuhkan untuk perebusan tergantung jenis dan ukuran ikan yang berkisar antara 30-40 menit. Menurut (Tim BSE 2017), proses perebusan dilakukan selama 30-60 menit tergantung ukuran ikan yang diproses.

Sub sistem pemasaran ikan pindang dapat dilihat dari empat unsur dasar pada pemasaran yaitu $4 \mathrm{P}$ yang terdiri dari product (produk), price (harga), place (tempat) dan promotion (promosi) (Morrisan 2015). Unsur pertama yaitu produk dapat dilihat dari segi kualitas, dimana produk ikan pindang cukup baik dapat dinilai dari produk yang dihasilkan dan kebersihan lingkungan maupun peralatan produksi, sedangkan untuk kuantitas ikan pindang yang diproduksi setiap harinya sudah memenuhi kebutuhan pasar yang dapat dinilai dari 
produk ikan pindang yang habis terjual setiap kali pemasaran, meskipun terkadang beberapa kali masih terdapat produk yang tidak habis dijual. Unsur kedua yaitu harga, dimana harga jual ikan pindang bervariasi berdasarkan jenis dan ukuran ikan. Unsur ketiga yaitu promosi, dilakukan secara langsung ke konsumen, seperti dengan menawarkan produk pada saat penjualan dan menawarkan ke warung-warung terdekat untuk dijual kembali. Unsur keempat yaitu tempat, dimana para pemindang memasarkan produknya ke pasar-pasar di wilayah Kabupaten Tabanan, dan pemindang juga memiliki langganan di warungwarung untuk dijual kembali.

Sub sistem lembaga/layanan pendukung sudah mendukung usaha yang dilakukan oleh anggota Poklahsar Pindang Panjul Segara, yang mencakup sarana dan prasarana, serta lembaga atau individu yang terkait di dalam suatu kegiatan bisnis perikanan (Sari, Yuniarti, dan Syamsuddin 2019).

\section{Analisis Usaha}

Biaya Investasi

Setiap pemindang memiliki jumlah biaya investasi yang berbeda-beda karena kepemilikan jenis dan jumlah peralatan produksi yang berbeda-beda. Biaya investasi terdiri dari biaya bangunan, peralatan produksi, kendaraan dan peralatan-peralatan lainnya. Biaya investasi dan biaya penyusutan dari tertinggi hingga terendah adalah Pemindang $B$ sebesar Rp 191.004.000, pemindang A sebesar Rp. 168.835 .000 dan pemindang $C$ sebesar Rp.164.754.

\section{Biaya Produksi}

Biaya Tetap

Biaya tetap terdiri dari biaya penyusutan, biaya listik, biaya air, biaya transportasi, biaya komunikasi, biaya ATK dan biaya pemasaran. Melihat dari biaya pemasaran, setiap pemindang mengeluarkan biaya pemasaran yang bervariasi, sebab biaya pemasaran berkaitan dengan lokasi pemindang memasarkan produknya. Pemindang memasarkan produknya secara langsung di pasar dengan membayar sejumlah biaya seperti biaya sewa lapak, biaya kebersihan dan keamanan. Biaya tetap dari tertinggi hingga terendah adalah Pemindang $B$ sebesar Rp 2.361.583, pemindang $A$ sebesar Rp 2.235.750 dan pemindang $C$ sebesar Rp 2.219.569.

\section{Biaya Variabel}

Biaya variabel terdiri dari biaya bahan baku, garam, tenaga kerja dan bahan-bahan lainnya. Biaya variabel tertinggi adalah pemindang $\mathrm{A}$. Hal ini disebabkan karena kapasitas produksi pemindang A paling tinggi. Biaya variabel pemindang A sebesar Rp 114.848.250, 
pemindang B, Rp 103.850.000,- dan pemindang C, Rp 67.612.500.

\section{Revenue Cost Ratio (R/C Ratio)}

Nilai $R / C$ ratio mengukur kelayakan suatu usaha yang menekankan pada nilai penerimaan dan pengeluaran. Ketiga pemindang memiliki nilai $\mathrm{R} / \mathrm{C}$ ratio yang sama yaitu 1,1 , artinya usaha yang dilakukan layak untuk dilakukan. Hal ini sesuai yang dinyatakan oleh Asnidar dan Asrida (2017) bahwa jika hasil perhitungan yang diperoleh $>1$, artinya usaha layak untuk diusahakan, jika $<1$, artinya usaha tidak layak untuk diusahakan dan jika $=1$, artinya usaha ada pada titik impas. Sehingga semakin tinggi nilai $R / C$ ratio semakin layak usaha tersebut dijalankan.

\section{Payback Period (PP)}

Seberapa cepat suatu investasi dapat kembali dapat diukur dengan menggunakan metode analisa usaha payback period (Zain, Triarso, dan Hapsari 2016). Semakin cepat pengembalian biaya investasi dalam suatu usaha, maka semakin baik pula usaha tersebut untuk dilanjutkan karena modal akan berputar dengan lancar.

Payback Period merupakan periode yang diperlukan dalam menutup pengeluaran investasi. Kriteria penilaian yaitu jika nilai PP kurang dari 3 tahun masuk dalam kategori cepat, nilai PP 3-5 tahun merupakan kategori sedang dan jika nilai lebih dari 5 tahun masuk dalam kategori lambat (Damayanti 2016).

Berdasarkan kriteria tersebut maka ketiga pemindang masuk ke dalam kategori cepat. Pemindang A memiliki waktu pengembalian modal paling cepat yaitu selama 0,9 tahun, dibandingkan dengan pemindang $B$ selama 1,2 tahun dan pemindang $C$ selama 1,7 tahun.

\section{Return of Invesment (ROI)}

Nilai $\mathrm{ROI}$ pemindang $A, B$ dan $C$ masing-masing adalah $13,6 \%, 12,3 \%$, dan 11,7\%. Artinya setiap Rp 100 yang diinvestasikan oleh pemindang $A$ akan menghasilkan keuntungan $\mathrm{Rp} 13,6$. Setiap Rp 100 yang diinvestasikan oleh pemindang $B$ akan menghasilkan keuntungan Rp 12,3. Setiap Rp 100 yang diinvestasikan oleh pemindang $\mathrm{C}$ menghasilkan keuntungan $\mathrm{Rp} 11,7$.

\section{Break Event Point (BEP) Rupiah \\ BEP rupiah pemindang $A, B$ dan $C$} masing-masing adalah $\mathrm{Rp}$ 15.969.642, Rp 18.166.023 dan Rp 17.073.607. Nilai tersebut adalah pendapatan per bulan yang minimal harus dicapai untuk mencapai titik impas. Artinya ketika mencapai nilai tersebut usaha pemindang berada pada titik impas, yaitu tidak untung dan titik rugi. Sehingga untuk mendapatkan keuntungan maka harus diperoleh nilai di 
atas nilai BEP rupiah tersebut. Berdasarkan analisa usaha, ketiga pemindang memiliki nilai BEP rupiah di atas titik impas, yang artinya menguntungkan.

\section{Break Event Point (BEP) Unit}

BEP unit dihitung berdasarkan jumlah jenis produk ikan pindang yang diproduksi oleh masing-masing pemindang. Berdasarkan analisa usaha, jika hasil BEP unit dibandingkan dengan jumlah produksi satu bulan, terdapat produk jenis ikan pindang yang tidak melewati titik impas, artinya pada jenis produk tersebut sebenarnya mengalami kerugian. Namun tertutupi oleh jenis produk lainnya sehingga total keseluruhan masih menguntungkan. Agar mendapatkan keuntungan dari semua jenis produk ikan pindang, maka jumlah produksi harus ditingkatkan melewati nilai BEP.

\section{Harga Penjualan Pokok (HPP)}

Harga penjualan pokok (HPP) adalah harga pokok dari produk sebagai patokan minimal harga jual agar tidak mengalami kerugian, sehingga untuk mendapatkan keuntungan maka produk ikan pindang harus dijual melewati HPP. Berdasarkan analisis usaha, jika hasil HPP dibandingkan dengan harga jual sekarang, terdapat harga produk jenis ikan yang kurang dari nilai HPP, artinya pada jenis produk tersebut sebenarnya mengalami kerugian. Namun tertutupi oleh jenis produk lainnya sehingga total keseluruhan masih menguntungkan. Agar mendapatkan keuntungan dari semua jenis produk ikan pindang, maka harga jual harus ditingkatkan melebihi nilai HPP.

\section{SIMPULAN}

Usaha pemindangan ikan oleh Poklahsar Pindang Panjul Segara dilakukan mulai dari penyediaan pasokan input, proses produksi, pasca produksi hingga pemasaran. Ketersediaan bahan baku, modal dan tenaga kerja serta penyediaan sarana dan prasarana telah terpenuhi sehingga kegiatan terlaksana dengan baik. Proses produksi pengolahan ikan pindang dilakukan melalui proses yang cukup baik sehingga menghasilkan produk ikan pindang yang layak dikonsumsi. Berdasarkan hasill perhitungan $\mathrm{R} / \mathrm{C}$ ratio dan $\mathrm{PP}$, maka usaha pemindangan ikan yang dilaksanakan oleh Pohlasar Pindang Panjul Segara layak untuk dilanjutkan.

\section{PERSANTUNAN}

Ucapan terimakasih penulis sampaikan kepada semua pihak khususnya kepada Poklahsar Pindang Panjul Segara yang telah memberikan dukungan, bimbingan, dan semangat dalam penulisan jurnal ini. 
DAFTAR PUSTAKA

Asnidar dan Asrida. 2017. "Analisis Kelayakan Usaha Home Industry Kerupuk Opak di Desa Paloh Meunasah Dayah Kecamatan Muara Satu Kabupaten Aceh Utara." Pertanian 1:39-47.

Assadad, Luthfi dan Bagus Sediadi Bandol Utomo. 2011. "Pemanfaatan Garam Dalam Industri Pengolahan Produk Perikanan." Squalen Bulletin of Marine and Fisheries Postharvest and Biotechnology 6(1):26.

Damayanti, Herna Octivia. 2016.

"Kelayakan Usaha Industri Ikan

Pindang Skala Rumah Tangga di Kabupaten Pati." Jurnal Litbang: Media Informasi Penelitian, Pengembangan dan IPTEK 12(1):22-31.

Fauzi, Syafril, Budhi Hascaryo Iskandar, Bambang Murdiyanto, dan Eko Sri Wiyono. 2011. "Kelayakan Finansial Usaha Perikanan Tangkap di Selat Bali." Jurnal Teknologi Perikanan dan Kelautan 2(1):37-46.

Judhaswati, Ratna Dewi dan Herna Octivia Damayanti. 2018. "Kelayakan Usaha Pengolahan Limbah Kulit Udang dan Rajungan (Studi di Kabupaten Situbondo dan Banyuwangi Provinsi Jawa Timur)." CAKRAWALA 12(2):118-36.

Karmini. 2018. Ekonomi Produksi
Pertanian. Samarinda (ID):

Mulawarman University Press.

Morrisan, M. A. 2015. Periklanan komunikasi pemasaran terpadu. Jakarta (ID): Kencana.

Pudjanarso, Amien. 2015. "Analisis Impas sebagai Dasar Pengambilan Keputusan Manajemen dalam Penentuan Luas Poduksi Minimal pada Industri Pemindangan Ikan Laut di Dusun Payangan Watu-Ulo Jember." RELASI Jurnal Ekonomi 11(1):67-86.

Sari, Santi Novita, Tatty Yuniarti, dan Syarif Syamsuddin. 2019. "Identifikasi Potensi Perikanan di Kecamatan Sindangkasih Kabupaten Ciamis Provinsi Jawa Barat." Jurnal Penyuluhan Perikanan dan Kelautan 13(1):7791.

Setiawan, Wahyu, Atikah Nurhayati, Titin Herawati, dan Asep Agus Handaka. 2018. "Kelayakan Usaha Penangkapan Ikan Menggunakan Jaring Insang (Gill Net) di Waduk Jatigede Kabupaten Sumedang." PAPALELE: Jurnal Penelitian Sosial Ekonomi Perikanan dan Kelautan 2(1):8-14.

Tim BSE. 2017. Pengolahan Hasil Perikanan Tradisional. Direktorat Pembinaan Sekolah Menengah Kejuruan Kemendikbud.

Wijayanto, Dian dan Faik Kurohman. 
2018. "Karakteristik Usaha Perikanan Tangkap Mini Purse Seine yang Berpangkalan di PPI Karanganyar Kabupaten Rembang." Jurnal Perikanan Tangkap: Indonesian Journal of Capture Fisheries 2(1):1-5.

Zain, Habieb Noor, Imam Triarso, dan Trisnani Dwi Hapsari. 2016.
"Analisis Kelayakan Finansial USAha Perikanan Tangkap Jaring Insang Permukaan (Surface Gill Net) di Pangkalan Pendaratan Ikan (Ppi) Banyutowo Kabupaten Pati." Journal of Fisheries Resources Utilization Management and Technology 5(1):162-69. 